\title{
E-beam-Cure Fabrication of Polymer Fiber/Matrix Composites for Multifunctional Radiation Shielding
}

\author{
J.W.Wilson ${ }^{*}$, B.J.Jensen ${ }^{\dagger}$, S.A.Thibeault ${ }^{\ddagger}$, Tan-Hung $\mathrm{Hou}^{\S}$ E. Saether ${ }^{* *}$, \\ E.H. Glaessgen ${ }^{\dagger}$, D.H.Humes ${ }^{\star}$ \\ NASA Langley Research Center, Hampton, VA 23681 USA \\ C.K.Chang ${ }^{\S \S}$, F.F. Badavi*** \\ Christopher Newport University, Newport News, VA 23606 USA \\ R. Kiefer ${ }^{\dagger \dagger \dagger}$ \\ College of William and Mary, Williansburg, VA 23186 USA \\ D.O. Adams \\ University of Utah, Salt Lake City, Utah USA
}

\begin{abstract}
Aliphatic polymers were identified as optimum radiation polymeric shielding materials for building multifunctional structural elements. Conceptual damage-tolerant configurations of polyolefins have been proposed but many issues on the manufacture remain. In the present paper, we will investigate fabrication technologies with e-beam curing for inclusion of high-strength aliphatic polymer fibers into a highly cross-linked polyolefin matrix. A second stage of development is the fabrication methods for applying face sheets to aliphatic polymer closed-cell foams.
\end{abstract}

\section{Introduction}

$\mathrm{T}$

HE International Space Station (ISS) typifies the first step in establishing space infrastructure by providing a base and possible transportation hub in low Earth orbit (LEO). The ISS is basically an aluminum structure providing a high technology readiness level (TRL9) for that historic development and represents current state-ofthe-art space habitat shielding (ref. 1). To enhance the radiation shielding properties of ISS, strategic placement of polyethylene augmentation (also TRL9) in crew quarters has helped in reducing exposures and optimization methods have been developed to minimize augmentation mass requirements (refs. 2,3). This present approach to spacecraft design involves the use of an aluminum shell to provide structural integrity combined with parasitic aliphatic polymer shield augmentation to supplement the radiation protection requirements (ref. 2). Such an approach tends to be heavy with large launch costs because the shielding material adds significant weight but does not carry load or provide damage tolerance to the spacecraft. We proposed novel multifunctional structural configurations to reduce spacecraft weight while maintaining radiation shielding, structural, and damage tolerance requirements using aliphatic polymeric fibers, foams, matrix, and adhesive materials (ref. 4).

\footnotetext{
${ }^{*}$ Senior Research Scientist, Analytical \& Computational Methods Branch/MS 188B, Member.

${ }^{\dagger}$ Senior Research Scientist, Advanced Materials Processing Branch/MS 226, Member.

${ }^{*}$ Senior Research Scientist, Advanced Materials Processing Branch/MS 226, Member.

${ }^{\S}$ Senior Research Scientist, Advanced Materials Processing Branch/MS 226, Member.

${ }^{* *}$ Research Scientist, Advanced Materials Processing Branch/MS 240, Member.

\# Senior Research Scientist, Advanced Materials Processing Branch/MS 240, Senior Member.

$\$$ Senior Research Scientist, Advanced Materials Processing Branch/MS 226, Member.

$\$ \$$ Professor, Department of Chemistry.

${ }^{* * *}$ Research Professor, Department of Chemistry.

iti Professor, Department of Chemistry.

Associate Professor, Department of Mechanical Engineering.
} 
A possible model of future space habitats is the recently studied Gateway Station shown in Fig. 1. The design is such that the required volume at launch is minimized by using inflatable wall structures attached to a central stiff structural column. Although such craft may never be built, they do represent design features required for future exploration habitats. A similarly constructed inspace transportation vehicle is shown in Fig. 2. In these conceptual designs, the central support column is constructed of aluminum while the inflatable section is the usual TransHab material lay-up using polyurethane foams, high strength fabrics, MLI, with an interior pressure bladder and has improved radiation shielding properties relative to aluminum (refs. 5,6). The advantages of replacing the polyurethane foam and highstrength fabrics by high-density polyethylene have been shown (refs. 7,8). In addition to enhanced shielding properties, there are other advantages to the use of such structures as shown in Fig. 3. The primary disadvantage is the low level of technology readiness of aliphatic polymeric structural systems.

A possible method of providing structural materials with good radiation protection properties is fabrication using high-density polyethylene fibers, epoxy matrix/adhesive, and polyethylene foams. Issues concern the poor bonding of epoxy to the polyethylene fiber and foam interfaces resulting in de-lamination and de-bonding as known failure modes (refs. 9,10) in addition of core shear failure. Both the bonding and core strength are enhanced by cross-stitching that results in a somewhat complicated fabrication process, especially for large irregularly shaped parts.

NASA needs to examine a number of options for the fabrication of multifunctional structural material concepts that provide efficient radiation shielding properties to allow down select to the most promising methods. One possible method of providing structural materials with good radiation protection properties is fabrication using high-density polyethylene fibers, epoxy matrix/adhesive, and polyethylene foams. Both the bonding and core strength are enhanced by crossstitching but results in a complicated fabrication process, especially for large irregularly shaped parts. Alternatively, core strength could also be enhanced by increase of cross-linking or increase of foam density (ref. 4). An alternate approach would be to develop means to form fiber, matrix, adhesive, transverse

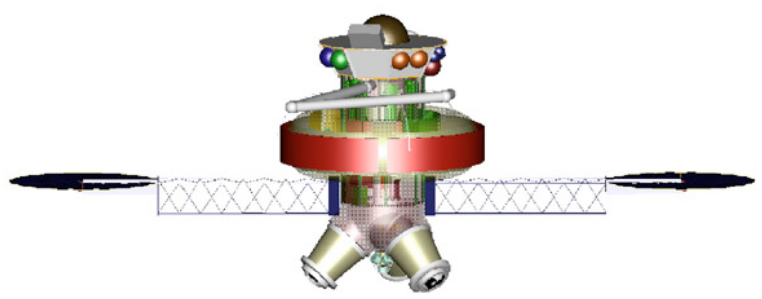

Fig. 1. Gateway Station.

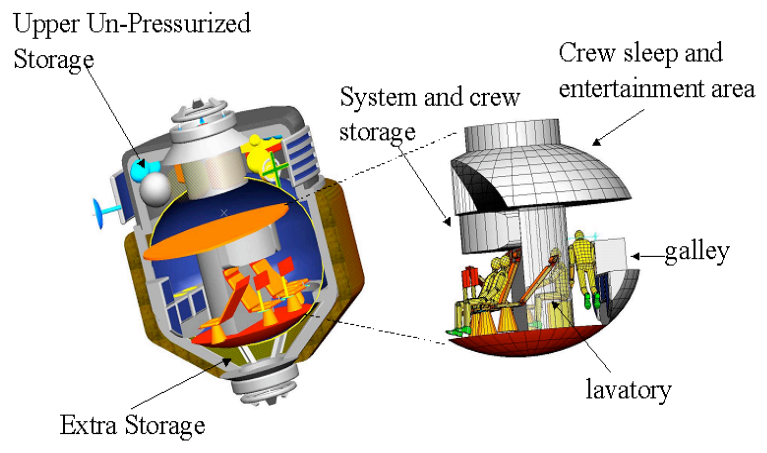

Fig. 2. Interior view of the Langley Crew Transfer Vehicle.

Aluminum versus Aliphatic Polymers

$$
\begin{array}{lc}
\text { Aluminum alloys } & \text { Aliphatic polymers } \\
\text { - Advantages } & \text { - Advantages } \\
\text { - TRL9 } & - \text { Insulating } \\
\text { - Well defined fabrication } & - \text { Sound absorbing } \\
\text { technology } & - \text { Inflatable with improved } \\
\text { - Well understood } & \text { packing factor } \\
\text { mechanical properties } & - \text { Improved radiation } \\
\text { - Disadvantages } & \text { shielding performance } \\
\text { - Condensates on cold side } & \text { - Disadvantages } \\
\text { - Corrosion } & - \text { TRL 2-3 } \\
\text { - Sound reverberation } & - \text { Poorly understood thermo- } \\
\text { - Poor radiation shielding } & \text { mechanical performance } \\
\text { performance } & - \text { Undeveloped fabrication } \\
\text { - Requires added thermal } \\
\text { management }
\end{array}
$$

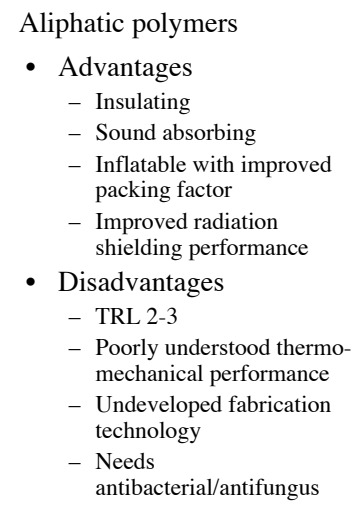

Fig. 3. Relative merits of Aluminum and Aliphatic polymers structural concepts.

reinforcement (if needed), and foam materials into a chemically monolithic structure with excellent radiation shielding properties while maintaining the physical in-homogeneities that provide structural strength and damage tolerance. It is anticipated that this monolithic/in-homogeneous structure will overcome de-bonding, de-lamination, and strength issues while providing efficient radiation shielding.

An ongoing multifunctional damage-tolerant stiff structural shielding development (ref. 4) is a direct extension of prior damage-tolerant stiff structures (refs. 9,10) by changing out graphite fabrics in face sheets and switching polyurethane foams by polyethylene. Such an approach had the advantage of building on earlier fabrication technology and already understood structural constructs. Earlier work had already posed one solution for the debonding of face sheet and polyethylene foam interface by introducing transverse stitching as seen in fig. 4 . We desire to eliminate or reduce de-bonding effects by better material match at the adhesive/foam interface thus possibly eliminating the need for the complicated transverse stitch. An attendant issue is the foam shear that is a 
consideration of this study. In addition, there is concern for the integrity of the Spectra fiber/epoxy interface leading to insufficient stiffness and de-lamination failure. We desire first to improve the matrix/fiber interface to reduce the de-lamination failure mode.

\section{Improved Fiber/Matrix Interface}

A principal failure mode of laminar matrix/fiber composites is de-lamination. This mode depends on the bonding of the matrix to the fibers. Normal bonding occurs through the adhesive properties of the matrix and the fiber materials. Maximum bond strength occurs for covalent bonded interfaces in which the matrix and fiber become chemically indistinguishable (still different in physical properties). Aliphatic matrix and fiber materials make such a conception possible leading to possible elimination of this failure mode in the face sheets. At first glance such a possibility would seem hard to achieve but is in fact quite simple and resulting in a method easily extendable to processing of even more complex objects. Thereby simplifying fabrication

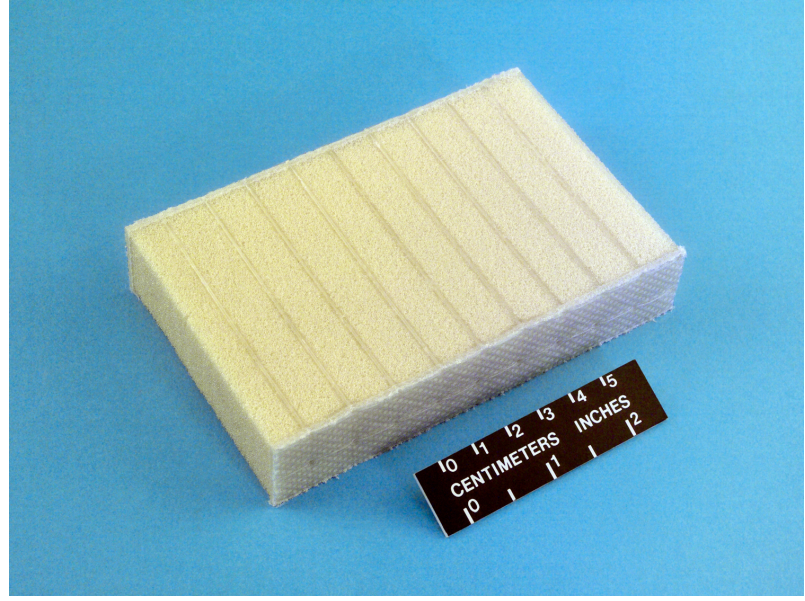

Fig. 4. Aliphatic fabric reinforced face sheets and foam core processes.

Polyethylene (PE) is not a well defined substance but is largely composed of $\left(-\mathrm{CH}_{2}-\right)_{\mathrm{X}}$. High-density $\mathrm{PE}$ has a large fraction of polymethylene that is highly crystallized at room temperature (melting point $\sim 132^{\circ} \mathrm{C}$ ). Commercially available Spectra is of this highly crystalline PE noted for its high tensile strength. So-called lowdensity polyethylene consists of long methyl chains with short-length side chains (mainly butyl, also methyl and ethyl) and some longer side chains (ref. 11). Butyl side chains are thought to form mainly from virtual carbon ring radicals being transformed to butyl by hydrogen transfer (so called back biting reaction). The low-density PE has internal crystallites and physical properties depend on degree of crystallization (lowest melting point $\sim 115^{\circ} \mathrm{C}$ forming a viscous liquid). Most low-density PE contains a small percentage (usually $<1 \%$ ) of carbon double bonds (ref. 12).

The radiolysis of PE is closely related to that of lower mass alkanes. Hydrogen is abstracted along the long chains followed by radical cross-linking forming a larger polymer complex and evolving hydrogen gas (ref. 13). The main cross-link reaction is

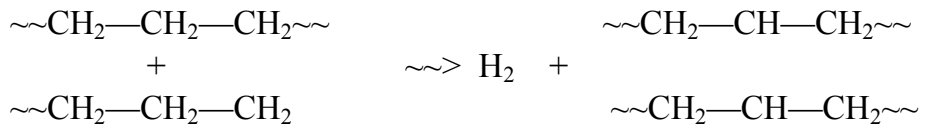

Short-length hydrocarbons (mainly butyl structures) are evolved by ionizing radiation from low-density PE in mainly unsaturated but also saturated states. Side chain fragmentation has some preference in the radiolysis of PE of which butyl dominates in most PE.

Up to about $\sim 4 \mathrm{Mrad}, \mathrm{PE}$ is only slightly cross-linked. Above 4 Mrads, PE cross linking produced a partially insoluble gel, continuing until at $700 \mathrm{Mrad}, \mathrm{PE}$ is converted into an insoluble polymer and the polymer no longer melts to form a viscous liquid but exhibits a rubber-like behavior (Fig. 5). Even modest crosslinking greatly improves (ref. 14) the useful temperature range and

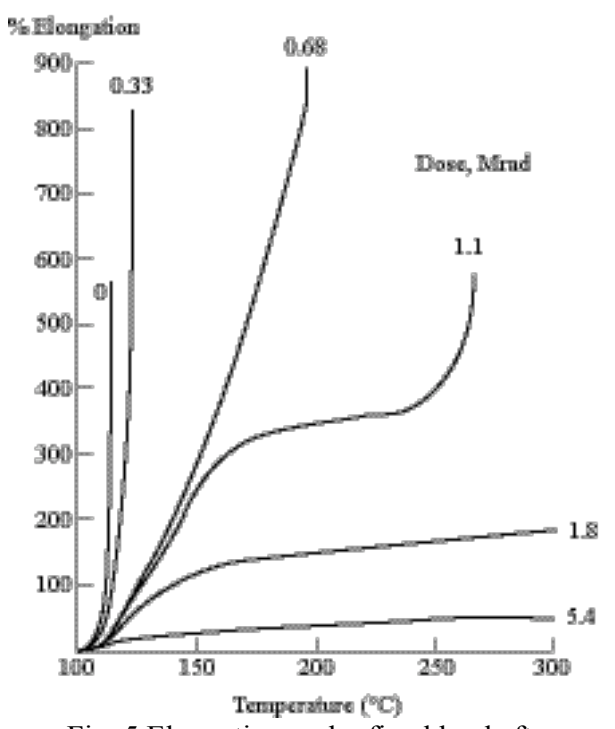

Fig. 5 Elongation under fixed load after irradiation of low density PE in vacuo (ref. 14). strength as seen in fig. 5. Irradiation in air forms carbonyl, carboxyl, and hydroxyl groups giving the external surface a waxy appearance. In the bulk, tensile strength increases as a result of cross-linking. On the other hand, radiolysis of thin films in air loses tensile strength (and gains mass) while thin films exposed in vacuo gain strength (and lose mass). Exposures of 10-20 Mrad of low-density polyethylene are typical of commercial preparation to 
maintain good structural properties over broad temperatures in commercial applications. After 60 to $70 \mathrm{Mrad}$, the polymer exhibits shape memory effects.

It was shown that exposure at the melting point of high-density Marlex-50 PE (85\% crystalline) doubled its amorphous content at $8 \mathrm{Mrad}$ (ref. 15). Similar exposures at room temperatures showed no significant loss of crystallization except when followed by fusion and cooling where significantly reduced crystallinity is observed relative to that of the exposures at high temperature. Reactor experiments (with unspecified PE type) on loss of crystallinity using cooling curves showed a degree of crystallinity remained to $\sim 70 \mathrm{Mrad}$ exposures at $80^{\circ} \mathrm{C}$ (ref. 16). After $\sim 1 \mathrm{Grad}$, the polymer is heavily cross-linked with the appearance of a dark-tinted transparent glass (ref. 12). It

$\begin{array}{lcccc} & & \text { Paraffins } \\ & & & \\ & & M W & C & T_{m} \\ \text { Decane } & \mathrm{C}_{10} \mathrm{H}_{22} & 142 & 10 & 243.5 \\ \text { Undecane } & \mathrm{C}_{11} \mathrm{H}_{24} & 156 & 11 & 247.6 \\ \text { Dodecane } & \mathrm{C}_{12} \mathrm{H}_{26} & 170 & 12 & 263.6 \\ \text { Tridacane } & \mathrm{C}_{13} \mathrm{H}_{28} & 184 & 13 & 267.8 \\ \text { Tetradecane } & \mathrm{C}_{14} \mathrm{H}_{30} & 198 & 14 & 279 \\ \text { Pentadecane } & \mathrm{C}_{15} \mathrm{H}_{32} & 212 & 15 & 283.1 \\ \text { Hexadecane } & \mathrm{C}_{16} \mathrm{H}_{34} & 226 & 16 & 291.3 \\ \text { Octadecane } & \mathrm{C}_{18} \mathrm{H}_{38} & 254 & 18 & 301.3 \\ \text { Eicosane } & \mathrm{C}_{20} \mathrm{H}_{42} & 282 & 20 & 309.8 \\ \text { Tetracosane } & \mathrm{C}_{24} \mathrm{H}_{50} & 338 & 24 & 323.8 \\ \text { Pentacosane } & \mathrm{C}_{25} \mathrm{H}_{52} & 352 & 25 & 326.7 \\ \text { Hexacosane } & \mathrm{C}_{26} \mathrm{H}_{54} & 366 & 26 & 329.5 \\ \text { Dotriacontane } & \mathrm{C}_{32} \mathrm{H}_{66} & 450 & 32 & 342.5 \\ \text { Tritriacontane } & \mathrm{C}_{33} \mathrm{H}_{68} & 464 & 33 & 344.3 \\ \text { Hexatriacontane } & \mathrm{C}_{36} \mathrm{H}_{74} & 506 & 36 & 349.1 \\ \text { Tetratetracontane } & \mathrm{C}_{44} \mathrm{H}_{90} & 618 & 44 & 359.6 \\ \text { Pentacontane } & \mathrm{C}_{50} \mathrm{H}_{102} & 702 & 50 & 365.3 \\ \text { Polyethylene } & \left(-\mathrm{CH}_{2}-\right)_{\mathrm{x}} & 980 & 70 & 414.6 \\ & & & & \\ \text { Polypropylene } & {\left[-\mathrm{CH}_{2}-\mathrm{CH}(\mathrm{CH} 3)-\right] \mathrm{x}} & 460.7 \\ & & & & \\ \text { Polyethylene } & { }^{2} \mathrm{Tg} & & & \\ \text { Polypropylene } & 237 & & & \\ 270 & & & \end{array}$

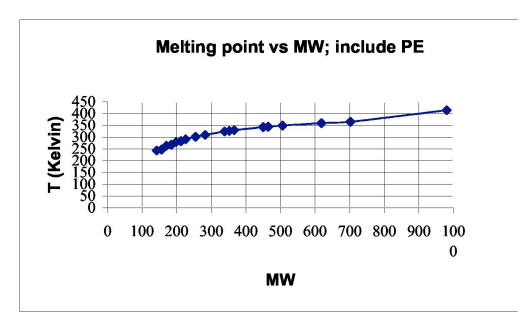

Fig. 6 Melting points of alkanes a

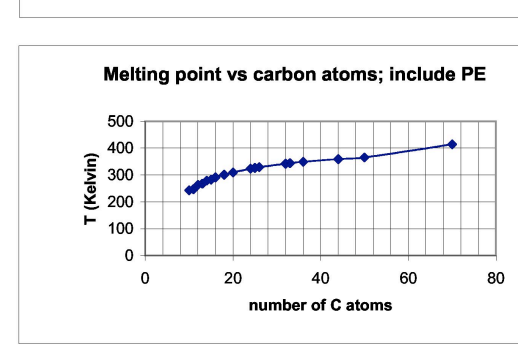

and polyolefins (far right entry at arbitrary mass). is hard and very brittle. In passing from low to high reactor exposures $\left(\sim 80^{\circ} \mathrm{C}\right)$, low-density PE density initially decreases from $0.92 \mathrm{~g} / \mathrm{cm}^{3}$ to a minimum of $0.9 \mathrm{~g} / \mathrm{cm}^{3}$ at about $300 \mathrm{Mrad}$ as crystallites are destroyed followed by a rise in density reaching $\sim 0.99 \mathrm{~g} / \mathrm{cm}^{3}$ at 4.5 Grad (ref. 17) as the polymer becomes highly cross linked.

The elastic modulus of PE exposed below 4 Mrad decreases with temperature until the melting point is reached. The decrease in modulus is related to melting of crystallites. Note also that the modulus at room temperature also decreases with increasing exposure on this range to 4 Mrad. Exposed PE on the range of 8 to 240 Mrad show higher modulus with dose at room temperature and this modulus decreases with temperature through $\sim 115-130^{\circ} \mathrm{C}$ (does not melt) followed by increasing modulus to higher temperatures. Above, $240 \mathrm{Mrad}$, the modulus continues to increase at room temperature with exposure and becomes less dependent on temperature and exhibits no rubber like behavior (ref. 17).

Another possibly useful polyolefin is polypropylene (PP); a highly crystallized material giving rise to high strength and melting point $\left(\sim 140^{\circ} \mathrm{C}\right)$. The methyl side groups are subject to loss in radiation exposure but PP is still known for its relatively high degree of cross linking (ref. 18). The transition to gel under irradiation ( $\sim 50 \mathrm{Mrad})$ is well defined from viscosity studies (ref. 19). Radiation exposure in air is subject to oxidation and treatment is best in inert atmosphere or in vacuum.

We have several possible approaches to forming polyolefin matrix/fiber composites. We will use a high-density alkane with their relatively low melting temperatures (see Fig. 6) as a pre-cure matrix with PE or PP fabrics. PP fabrics may be preferred because of their high inherent crystallinity and good adhesion to PE matrix. The alkane matrix/fiber composite will be cured using an e-beam (Fig. 7). This will not only cross link the alkane into a PE polymer but cross link the matrix material to the fiber material resulting in a single chemical unit but physically inhomogeneous for the desired structural properties. We will examine both the simple polymer form (PE/PE) and the copolymer form (PE/PP) of laminar composites. This work will be done with commercially available

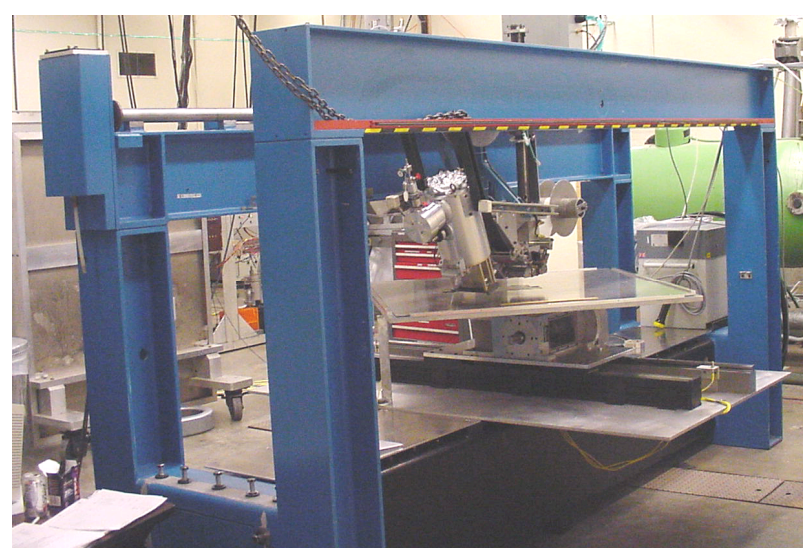

Fig. 7 Langley ebeam processing facility. fabrics. Parameters of the fabrication process to be studied are: temperature and pressure in forming the alkane matrix/fabric composite, dose of the curing process, heat treatment of final product against the mechanical properties of the composite and de-lamination failure. 


\section{Improved Face Sheet/Foam Interface}

Sandwich structural components satisfy the need for damage tolerance and result in low mass as required for space systems. Above we discussed the development of laminar composite systems with good radiation protection properties. These are used to provide loadbearing face sheets in the composite sandwich. The sandwich core will be polyolefin closed cell foam. The foam maintains separation of the face sheets for improved stiffness and also damage tolerance from impacts. Essential to stiffness is the need to maintain separation distance of the face sheets by providing a strong bond between the face sheets and core.

E-beam curing of the alkane matrix provides

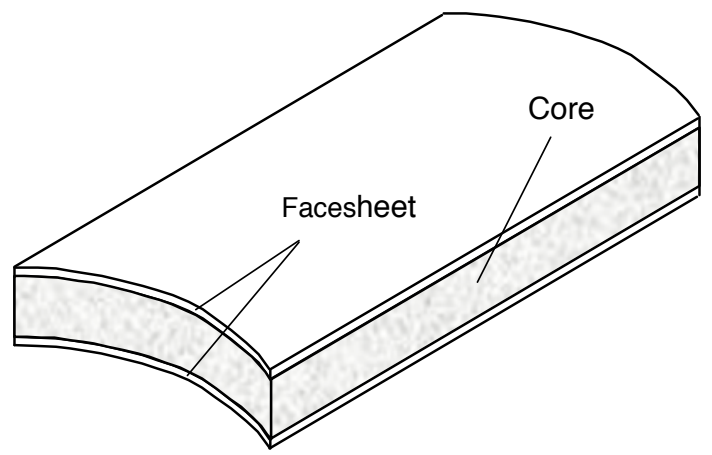

Figure 8. Sandwich composite structure. opportunity for strong bonding to the core foam. The face sheets and core bond can be set by taking the foam/fabrics and impregnating them with alkane in a low temperature/pressure press. Choosing the core to be a polyolefin adds radiation protection properties. Cross-linking with e-beam cure allows the fiber/matrix/foam to become a single covalently bonded structure and allows one to adjust strength properties. The use of PE or PP core allows the alkane melt to wet all surfaces prior to cure. Use of polymethylene PE allows higher press operating temperatures while even higher temperatures are allowed by PP. An example of the final product is indicated in Fig. 8.

The goal of this research is to develop an efficient sandwich composite fabrication technology that is simpler than the stitched sandwich and able to improve on its protection characteristics from radiation and meteoroid impact while improving mechanical strength. The study results on laminar composites will limit fabrication parameters of the sandwich composites. We will investigate the effects of fabrication parameters on sandwich composites as follows: temperature and pressure in forming the alkane matrix/fabric/foam composite, dose of the curing process, core density, "Z-fiber" number (if required, D. O. Adams), heat treatment of final product against the mechanical properties of the composite and de-bonding failure.

\section{Testing Protocols}

Several categories of mechanical tests will be conducted to assess the structural performance of the candidate composite face sheets and multi-functional sandwich configurations produced in this phase. We will perform de-lamination fracture toughness test on the laminated face sheets using crack opening and sliding shear tests. Crack opening tests will be performed using the double cantilever beam test shown in Fig. 9. This test evaluates the inter-laminar bonding within the face sheets.

Core shear testing will be used to assess the capacity of the candidate sandwich configurations to carry inter-laminar shear loads. Although this test method does not produce a state of pure shear stress within the core, the secondary stresses have a

Double Cantilever Beam (DCB) Test

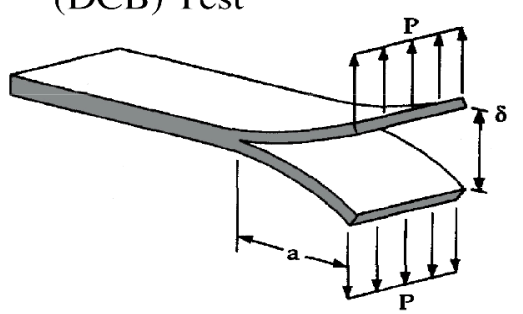

Fig. 9. Double Cantilever Beam de-lamination test

Mixed Mode Bending Test

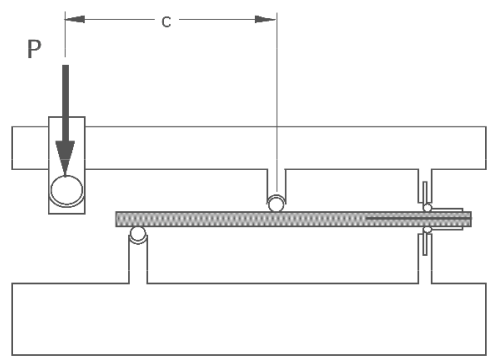

Fig. 10. Three point mixed mode bend test. minimum effect when the proper length specimen is used. The core shear test is similar to a simple lap shear test, however the load is applied such that the sandwich specimen is loaded at a slight angle to the plane of the face sheets. Fixtures are used that enabled a tensile load to be applied through a line connecting opposite corners of the sandwich specimen as shown in Fig. 11. Stitching has the potential to double the shear strength $($ refs. 9,10) and the use of Z-fibers can also be used to strengthen the present application if necessary. 
Three-point flexure testing will provide an assessment of each sandwich configuration under a combined stress state. Under three-point flexure loading, a sandwich specimen will experience tensile and compressive stresses in the face sheets as well as significant shear stresses in the core. Thus, flexure testing will be used to identify performance problems associated with either material. By calculating the area under the load versus crosshead deflection curve, these tests will provide an estimate of the energy absorption capabilities of the sandwich configuration under flexural deformation. The important properties to be obtained from these tests are the flexural strength, the failure mode(s) observed, and the energy absorbed to failure. Where appropriate, damage will be documented with dye-enhanced cross-sectional photographs.

Damage tolerance testing will also be performed on the candidate multifunctional sandwich panels. Similar to the mechanical tests, test configuration will be made following preliminary design rules for meteoroid/debris guidelines. Assuming an example face sheet material of high-strength polymeric fabric (e.g., Spectra), Table 1 lists the required separation, $\mathrm{S}$, and relative thicknesses of the fabric sheets needed to meet the impact criterion for encountered high-velocity objects $(10 \mathrm{~mm}$ projectile, $10 \mathrm{~km} / \mathrm{s}$, refs. 20,21). The exterior face sheet requires sufficient thickness to shatter the projectile and $\mathrm{S}$ designates the fragment diverging drift region. Depending on the projected impact area on the interior face sheet determined by S, the interior sheet thickness is determined. The parameters assume near unit density materials for face sheets and sufficiently low-density foam to prevent "channeling" of the fragments where by impact energy density on the interior sheet is reduced thereby reducing the probability of penetration of the

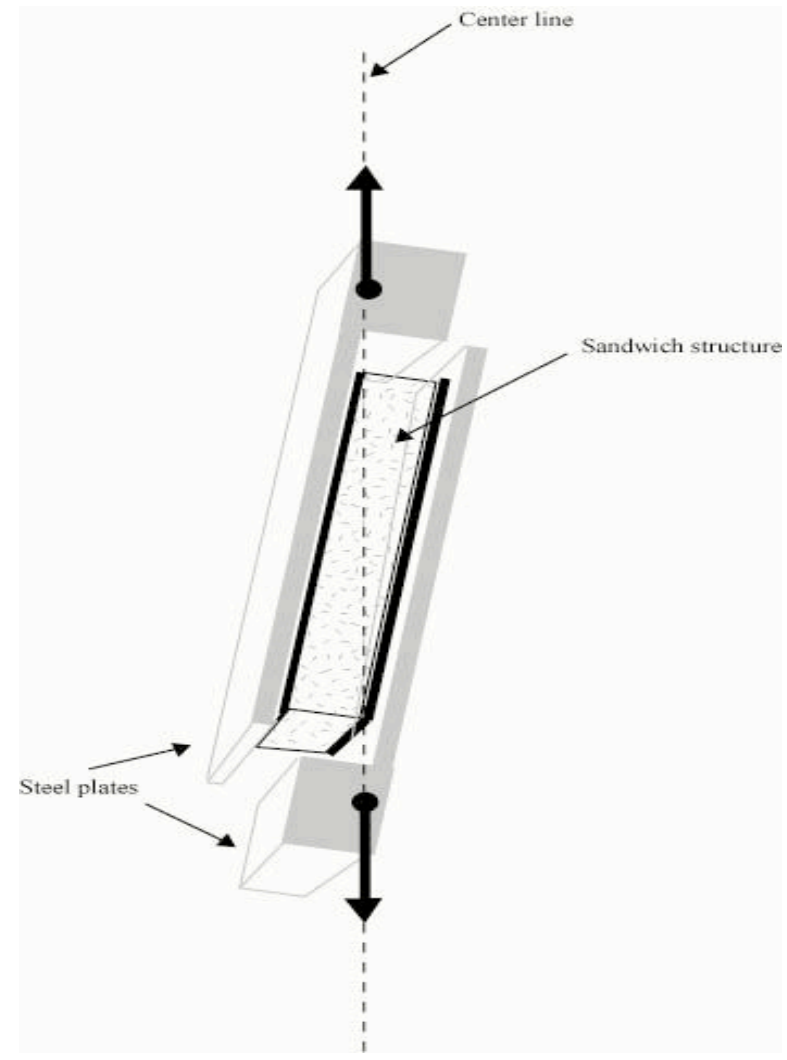

Fig. 11. Core shear test rig. pressure vessel.

Testing will involve the formation of damage by a prescribed impact event with assurance of no penetration followed by a mechanical test to assess mechanical performance reduction. Options for impact testing include lowspeed drop weight impacting (to investigate handling damage) and hypervelocity impact to simulate (debris/meteoroid damage). Options for post-impact testing include flexure and edgewise compression

Radiation transmission testing will be performed in collaboration with the Lawrence Berkeley National Laboritory (LBNL) team using the Brookhaven National Laboratory (BNL) ion beam exposures (ref. 3) and LBNL proton beam exposures. There are seven ions that are responsible for $85 \%$ of GCR dose equivalent behind a shield material (ref. 5). We will test the transmission of the resulting materials to these ions $(\mathrm{H}, \mathrm{He}, \mathrm{O}, \mathrm{Si}, \mathrm{Ca}, \mathrm{Mn}, \mathrm{Fe})$ as recommended protocols by the 1995 JSC workshop (ref. 5) and adopted as protocols in the 2000 LBNL workshop.

\section{Concluding Remarks}

An innovative fabrication method for a stiff damage-tolerant structural element based on a multifunctional structural approach using state-of-theart composite material systems with ebeam processing is presented herein. The thermal/mechanical properties has not been fully addressed in this preliminary effort but compatible aromatic/aliphatic monomer systems development for radiation protection optimization while meeting

Table 1 Parameters for simple "Whipple" shield arrangement

\begin{tabular}{||l|l|}
\hline Element & $\begin{array}{l}\text { Minimum } \\
\text { thickness, mm }\end{array}$ \\
\hline $\begin{array}{l}\text { Exterior } \\
\text { face sheet }\end{array}$ & 2 \\
\hline Foam core & $\mathrm{S}$ \\
\hline $\begin{array}{l}\text { Interior } \\
\text { face sheet }\end{array}$ & $3 \times 10^{4} / \mathrm{S}^{2}$ \\
\hline
\end{tabular}
conditions of the service environment is the next logical step in this study. 


\section{References}

${ }^{1}$ C.P. Hugger, J.E. Nealy, M.S. Clowdsley, et al. Preliminary Validation of an ISS Radiation Shielding Model. AIAA 2003-6220, Sept. 2003.

${ }^{2}$ G.D. Qualls, J. W. Wilson, F.A. Cucinotta, et al. International Space Station Radiation Shield Augmentation Optimization. AIAA 2003-6222, Sept. 2003.

${ }^{3}$ Miller, J., Zeitlin, C., Cucinotta, F. A., et al., Benchmark studies of the effectiveness of structural and internal materials as radiation shielding for the international space station, Rad. Res, 159,381-390,2003

${ }^{4}$ J.W. Wilson, E.H. Glaessgen, B. Jensen, et al. Next Generation Shielding Materials for Earth Neighborhood Infrastructure. AIAA 2003-6258, Sept. 2003.

${ }^{5}$ J.W. Wilson, J. Miller, A. Konradi, and F. A. Cucinotta, eds., Shielding Strategies for Human Space Exploration, NAS CP 3360 , 1997.

${ }^{6} \mathrm{~J} . \mathrm{W}$. Wilson, et al. Issues in deep space radiation protection. Acta Astronautica 49:289-312; 2001.

${ }^{7}$ L.C. Simonsen, J.W.Wilson, M.H. Kim, F.A. Cucinotta, Radiation exposures for human Mars exploration. Health Phys. 79:515$525 ; 2000$.

${ }^{8}$ G.D. Qualls et al., Inter Crew Shielding Against a Solar Particle Event in L1. SAE 2002-01-2335, 2002.

${ }^{9}$ E. H. Glaessgen, et al. "Analyses for Debonding of Stitched Composite Sandwich Structures Using Improved Constitutive Models," 42nd AIAA/ASME/ASCE/AHS/ASC Structures, Structural Dynamics, and Materials Conference, AIAA-01-1279-CP, AIAA, Washington, DC, 2001.

${ }^{10}$ L. E. Stanley and D. O. Adams, "Evaluation of Stitched Composite Sandwich Panels Under Interlaminar Loading," Proceedings of the American Society for Composites, Blacksburg, VA, 2001.

${ }^{11}$ A.H. Willbourn, J. Am Chem. Soc. 34, 569, 1959.

${ }^{12}$ A. Chapiro, Radiation Chemistry of Polymeric Systems. Interscience Publishers, 1962.

${ }^{13}$ A. Charlesby, Proc. Roy. Soc. (London) A230, 120, 1955.

${ }^{14}$ A. Chapiro, J. Chim. Phys. 52: 246; 1955.

${ }^{15}$ T. Williams, H. Matsuo, and M. Dole, J. Am. Chem. Soc. 80, 2595, 1958

${ }^{16}$ A. Charlesby and M. Ross, Proc. Roy Soc. (London) A217, 122, 1953

${ }^{17}$ A. Charlesby and N.H. Hancock, Proc. Roy. Soc. (London) A218, 245, 1953

${ }^{18}$ A.A. Miller, E.J. Lawton, and J.S. Balwit, J. Polymer Sci. 14,503, 1954

${ }^{19}$ R.M. Black and J. Lyons, Nature 180, 1346, 1957

${ }^{20}$ Christiansen, E.L., Kerr, J.H.; Ballistic limit equations for spacecraft shielding. Int. J. Impact Engng 26: 93-104: 2001.

${ }^{21}$ Christiansen, E.L., Kerr, J.H.; Mesh double bumper shield: A low-weight alternative for spacecraft meteoroid and orbital debris protection. Int. J. Impact Engng 14: 169-180: 1993. 